recently dead father. The result was catastrophic for all concerned.

JOYCE L DUNLOP

De la Pole Hospital,

North Humberside

SIR,-Canon Kevin Byrne's excellent article (30 April, p 1399) makes me wonder if he has heard of the Institute of Religion and Medicine founded in 1964 as the result of an initiative by the then Archbishop of Canterbury, Michael Ramsay. This institute, with headquarters in London and field groups throughout the country, now has a membership of around 1000 and since its inception has done an enormous amount of valuable work in the sphere of doctor-clergy relationships and in the consideration of the many problems which confront both disciplines.

More recently members of the helping professions (nurses, social workers, health visitors, etc) have been added to the numbers and during my 30 years as a general practitioner when incidentally there were two interregnums in the parish where I worked, I found the institute of great help. By chance the present treasurer of the institute, the Reverend Christopher Cooke, now rector of St Marylebone Parish Church and at present deeply involved in a project of converting the crypt beneath the main body of the building into a centre for healing for all disciplines, had with myself the privilege of bringing his third child into the world in the enforced absence of a midwife. Both he and his splendid wife were quite excellent throughout the delivery, and I think we all regarded this event as a striking example of doctor-clergy cooperation.

Builth Wells,

Michael Platten

Builth Wells,
Powys LD2 $3 \mathrm{HH}$

\section{Unilateral somatic symptoms due to hyperventilation}

SIR,-Dr J N Blau and others (2 April, p 1108) reported a predominance of left sided symptoms in the hypoventilation syndrome but they did not mention the expanding list of other disorders with an emotional component in which a moderate excess of left sided symptoms is found. A survey of 512 hypochondriacal patients, of whom 301 had primary hypochondriasis and 211 had hypochondriasis secondary to another disorder, showed that $19 \%$ of the primary and $12.3 \%$ of the secondary group had unilateral symptoms. These were left sided in $65 \%$ of the primary group and in $80.7 \%$ of the secondary group. ${ }^{1}$ Likewise in hysterical disorders, carefully defined and diagnosed, a moderate excess of left sided symptoms appeared, which was more marked in women than in men. ${ }^{2}$ In addition, a small group of patients with "non-articular rheumatism" showed a substantial excess of left sided symptoms-13 out of 14 patients. $^{3}$

It seems unlikely that the predominance of left sided symptoms is a nosocomial artefact since right sided symptoms might be expected to cause more disability and therefore present more frequently to doctors. Many explanations have been offered for this phenomenon including psychological, psychoanalytical, sociological, and neurological formulations. One theory is that the right hemisphere is activated to a greater extent than the left during stress, and some evidence has been advanced for this hypothesis in normal volunteers. ${ }^{4}$ Against this is the finding of symmetrical changes in the electroencephalogram in those with unilateral symptoms on hyperventilation. ${ }^{5}$ The most parsimonious explanation of the findings in the hyperventilation syndrome may well be a functional asymmetry in the peripheral nerves and their nutrient vessels, as suggested by Dr Blau and others. It would be difficult however, to explain the asymmetry in the other disorders according to this mechanism. The origin of the asymmetry therefore remains mystery but it seems likely that a central mechanism will be implicated, particularly in hysteria and hypochondriasis.

Maudsley Hospital,

C THOMPSON

Kenyon FE. Hypochondriasis: A clinical study. $\mathrm{Br} \mathcal{F}$ Psychiatry 1964;110:478-88.

Galin D, Dimond R, Braff D. Lateralisation of conversion symptoms more frequent on the left. $A m \mathcal{F}$ Psychiatry 1977;134:578-80

Halliday JL. Psychological factors in rheumatism. Br Med f 1937;i:264-9.

ucker DM, Roth RS, Arneson BA, Buckingham V.

Right hemisphere activation during stress. Neuro
psychologia 1977; 15:697-700.
Tavel ME. Hyperventilation syndrome with unilatera somatic symptoms. ₹AMA 1964;187:301-3.

\section{Total parenteral nutrition}

SIR,-The Oxford parenteral nutrition group (23 April, p 1323) advocate the use of standard regimen in which dextrose and Synthamin are contained in a single bag and a $500 \mathrm{ml}$ bottle of Intralipid is connected to a side port of the infusion apparatus. Since the introduction of the ethylene vinyl acetate bag it has been possible to combine Intralipid with dextrose and Synthamin in the single 31 bag. This has the advantage of simplifying administration and reducing the number of connections.

So far we have prescribed more than 400 bags containing Intralipid without adverse effect, and bags containing lipid are routinely used for patients on home parenteral nutrition. Furthermore, in one such patient hypersensitivity reactions were previously associated with the separate infusion of Intralipid, but no such reaction was observed when the Intralipid was mixed with other nutrients, ${ }^{1}$ possibly reflecting increased dilution or duration of administration. Contrary to the experience of the Oxford group we have observed abnormal liver function tests, with an increased concentration of alkaline phosphatase and $\gamma$-glutamyl transpeptidase, in all patients who received tota parenteral nutrition for more than two weeks with dextrose as the single energy source. We found no abnormalities, however, when part of the energy was supplied as lipid with a consequent reduction in the amount of dextrose infused.

\section{R PENNINGTON J M RICHARDS}

\section{Medical Unit, King's Cross Hospital
Dundee DD3 8EA}

' Pennington CR, Ritchie P, Pringle R. Home parenteral nutrition. The first twelve months. Scot Med $\mathcal{J}$

\section{Responsibility for prescribing}

SIR,-Once or twice a year I feel ashamed to feature on the medical register. Dr John Ball and the General Medical Services Committee (30 April, p 1456 and 7 May, p 1526) do not make life any easier.
General practitioners are worried about the motives of those who would wish them to prescribe fluids for patients having continuous ambulatory peritoneal dialysis. Or, as $\mathrm{Dr} \mathrm{Ball}$ puts it, they are fearful of becoming a target for "blackmail." Or to put it another way: "He [Dr Ball] did not ... want to see his colleagues put in a position whereby they were providing services that were outside their control and outside their clinical remit ... the arrangement in the West Midlands was simply a manipulation of a hospital controlled activity."

Suppose my family doctor sends me to hospital, where a consultant confirms the diagnosis of diabetes. The consultant writes to my doctor advising an insulin regimen naturally, he would be happy to see me in the outpatients department from time to time. Does the general practitioner refuse to prescribe insulin? Suppose my doctor sends me to a renal physician, who confirms kidney failure. The physician inserts a peritoneal catheter and writes to my doctor advising a dialysate regimen: naturally, he would be happy to see me in the outpatient department from time to time. Should the general practitioner refuse to prescribe dialysate?

The renal physicians in Birmingham Central district cannot afford continuous ambulatory peritoneal dialysis fluids. What are they to do ? Send me home to die in the arms of my general practitioner? Or should they not encourage the Department of Health and Social Security, in the person of Sir Kenneth Stowe, its permanent secretary, to transfer the cost to a family practitioner committee ?-a tough proposition. Like the treasury, the department unfairly bears the reputation of an inverted $\mathrm{Mr}$ Micawber: always waiting for something to turn down.

If $\mathrm{Sir}$ Kenneth, who earns my respect, then actually does agree to what is essentially an exercise in accountancy-admittedly he was in something of a spot-we should raise at least two cheers for democracy. Provided a family practitioner committee does not penalise a practice for over prescribing, here is a formula which lightens the burden imposed on the hospital service by the "no growth" diktat and yet makes sure the patien who needs help gets it. A classic British compromise; but then the National Health Service always has been a financial madhouse

We so often hear Dr Ball and his colleagues say how important primary care is and how they, and not the hospital consultant, should assume continuing responsibility for patients What has changed?

Bromsgrove General Hospital,

P V ScotT

Bromsgrove,
Worcs, B61 $0 \mathrm{BB}$

Correction

Is dexamethasone deleterious in cerebral malaria?

We regret that an error occurred in the letter by Dr D A Warrell (23 April, p 1355). The sixth sentence of the sixth paragraph should have read: "Mortality was $65 \%$ in patients with parasite counts more than $250000 / \mu$ and $43 \%$ in those with counts more than $100000 \mu / 1$, compared with an overall mortality of $21 \%$

.

